\title{
Investigations of thermoluminescent silica beads of different manufacturers and colours
}

\author{
K. Ley ${ }^{\mathrm{a}, *}$, S.M. Jafari ${ }^{\mathrm{b}}$, A. Lohstroh ${ }^{\mathrm{a}}$, D.A Bradley ${ }^{\mathrm{a}, \mathrm{c}}$ \\ ${ }^{a}$ Department of Physics, University of Surrey, Guildford, Surrey, GU2 7XH, UK (Member of SEPnet) \\ ${ }^{b}$ Queen Alexandra Hospital, Portsmouth, Hampshire, UK \\ ${ }^{c}$ Sunway University, Institute for Healthcare Development, 47500 Subang Jaya, Selangor, Malaysia
}

\begin{abstract}
Increased interest in silica based materials for use in medical thermolumiscence (TL)-based dosimetry has led to investigations of tailoring different types of technologies for specific uses. Here we study a low-cost approach to the harnessing of this emerging dosimetry technique, utilising commercially manufactured doped silica beads. The beads have been previously studied using two well-established TLD Reader systems, namely the HARSHAW and TOLEDO brands, and are now being studied making use of a Risø TL/OSL system, a more modern and also highly sensitive facility. Characterisation studies have been conducted and results from this have been compared against that of existing literature including glow-curves and colour study TL-yield responses. The outcome confirms that colourless beads produce the highest yield when observing the $2.7 \mathrm{eV}$ electron trap of silica based materials with TLD techniques. Investigations have also been made concerning the batch homogeneity of coloured beads from two different manufacturers, Mill Hill, Japan and Toho Czech, and different physical finishes of the silica beads, transparent or frosted. Studies also show that the colourless beads displaying the best batch homogeneity overall are those produced by Mill Hill Japan, measured by the percentage difference from the average TL yield, with the clear petite beads displaying the best homogeneity.
\end{abstract}

Keywords: Thermoluminescence (TL), Silica, Dosimetry, Ris $\varnothing$ TL/OSL

\section{Introduction}

In recent years interest has grown in using silica doped materials as dosimeters, most generally for medical applications (Jafari et al., 2014a; Abdul Sani et al., 2014) including for in vivo dosimetry (O'Keeffe et al., 2015; Mizanur Rahman et al. 2015). It has been identified that silica doped materials possess properties suitable for electron trapping when exposed to ionising radiation. These electrons can then be released from the coulomb traps by means of excitation,

\footnotetext{
*Corresponding author

Email addresses: k.ley@surrey.ac.uk (K. Ley), s.jafari@surrey.ac.uk (S.M. Jafari), a.lohstroh@surrey.ac.uk (A. Lohstroh)
}

either with heat or light. The means of excitation in this study is the release of electrons using heat, a process called thermoluminescence. Conversely there are also other means of treating the material to obtain a luminescent response such as Optically Stimulated Luminescence (OSL) and Radio-Luminescence (RL), such that under the right conditions both of these techniques can be used in order to gather information about doses resulting from irradiation. While many luminescence dosimetry studies focus on the thermoluminescent characteristics of these materials Alawiah et al., 2017, Rozaila et al., 2016; Jafari et al. 2014b), other such investigations point to developing the possibility of online dosimetry using OSL and RL (Mizanur Rahman et al., 2016; 
Woulfe et al., 2013). Studies in the structure of silica have also shown a rise in interest recently, bringing more of an understanding as to the mechanisms that contribute to the luminescence phenomenon. Works by Bachiller-Perea et al. (2015) shed light on the electron traps corresponding to the two peaks currently studied in TL dosimetry of silica, with depths of $1.9 \mathrm{eV}$ and $2.7 \mathrm{eV}$ emitting $\sim 460 \mathrm{~nm}$ and $\sim 650 \mathrm{~nm}$ light respectively.

Studies herein focus on the TL properties of variously doped silica. The silica doped beads, materials that are widely available in craft shops for jewellery purposes, are of particular interest for use as dosimeters for a number of reasons. Firstly, unlike the doped silica optical fibres that are often tailor made or altered before use as a dosimeter (Bradley et al., 2014), the beads are produced commercially and are only required to be prepared for TL dosimetry using elementary surface treatments. As they are commercially produced on a large scale they are also cheap to purchase and can be ordered in bulk quantities. Thirdly, while the size and geometry of the beads are such that they can still provide high spatial resolution dosimetry techniques, they are clearly easier to store and handle than doped silica fibers. There is also the property that glass is chemically inert opening up the possibility of in vivo dosimetry.

Previous studies have shown detectable TL yields for commercially available silica beads (Jafari et al., 2014b), thus said continuation of this work examines the extent to which the finish of the various beads affects the TL yield, also of the homogeneity of response. In present efforts, it is to be noted that all characterisation has been made using one of the most modern designs of TL/OSL readers. The previously used TLD readers for silica bead studies have been HARSHAW and TOLEDO readers, now surpassed by new detector systems that are capable of reading more than one sample at a given time, exemplified by the Risø TL/OSL reader.

\section{Materials and Methods}

All beads investigated are produced such that they have an inner concentric hole to provide for them to be threaded onto say a bangle or necklace, also being available in various single colours. Beads investigated from manufacturer Toho, from the Czech Republic, were of two forms, in both forms the beads being mass produced. One form of Toho beads consitst of an outer diameter ranging from $1.46 \mathrm{~mm}$ to $2.30 \mathrm{~mm}$ and a frosted finish, while beads of the other form have outer diameters $1.24 \mathrm{~mm}$ to $1.46 \mathrm{~mm}$ and were transparent. The Mill Hill beads from Japan that were studied herein were, with the exception of the frosted white beads, all transparent, the beads varying in outer diameter for specific beads; the clear petite, light bronze and dark blue beads were of outer diameters ranging from $1.58 \mathrm{~mm}$ to $1.63 \mathrm{~mm}$ while the others were of outer diameters ranging from $2.17 \mathrm{~mm}$ to $2.20 \mathrm{~mm}$. The resolution of the digital caliper that was used to make the measurements was $0.01 \mathrm{~mm}$. The sample size for Toho beads was from 28-30 beads per colour, except for the blue and maroon beads; for the latter, as a result of the height restriction placed upon the samples (see section 2.5), these had a sample size of from 16 to 23. For the Mill Hill beads fewer beads had to be discounted from readout and sample sizes where within the range of 24-29 beads per colour. The difference in physical appearance of the beads as a result of the two different finishes is demonstrated in Fig. 1 and Table 1.

\subsection{Cleaning}

A fraction of the beads arrived from the manufacturers complete with a metallic coating, a surface dressing that prior to annealing needed to be removed to mitigate the possibility of oxidisation during annealing and readout. For such removal, all beads were washed in a $7 \%$ nitric acid solution, that was heated up to $60{ }^{\circ} \mathrm{C}$ and maintained for 5 mins and then cooled naturally, using a magnetic stirrer hot plate mixer (Ikamag RM, Janke \& Kunkel IKA Labortechnik); the process is aided by using a magnetic flea stirring device. 


\begin{tabular}{|c|c|c|c|c|c|}
\hline Bead Type & Photo & $\begin{array}{l}\text { Diameter } \\
(\mathrm{mm})\end{array}$ & $\begin{array}{l}\text { Average mass } \\
\text { normalised } \\
\text { TL yield } \\
\text { (counts } / \mathrm{mg})\end{array}$ & $\begin{array}{l}\text { Error in } \\
\text { mean } \\
(\%)\end{array}$ & $\begin{array}{l}\text { Error } \\
\text { in } \sigma \%\end{array}$ \\
\hline White (MH-F) & (1) & $2.17-2.20$ & $4.74 \times 10^{5}$ & 0.70 & 18.88 \\
\hline Clear Petite (MH-T) & (4) & $1.58-1.63$ & $4.48 \times 10^{5}$ & 0.30 & 7.76 \\
\hline Clear (MH-T) & (62) & $2.17-2.20$ & $3.77 \times 10^{5}$ & 0.88 & 24.69 \\
\hline White (To-F) & & $2.30-1.46$ & $1.44 \times 10^{5}$ & 0.79 & 14.96 \\
\hline Pink (MH-T) & (2) & $2.17-2.20$ & $9.94 \times 10^{4}$ & 0.91 & 21.77 \\
\hline Clear Blue (To-T) & 6 & $1.24-1.46$ & $1.19 \times 10^{4}$ & 0.58 & 17.52 \\
\hline Blue (MH-T) & (a) & $2.17-2.20$ & $9.63 \times 10^{3}$ & 1.44 & 38.99 \\
\hline Red (MH-T) & (a) & $2.17-2.20$ & $8.48 \times 10^{3}$ & 0.10 & 2.64 \\
\hline Yellow (To-F) & $a$ & $2.30-1.46$ & $8.45 \times 10^{3}$ & 0.75 & 21.71 \\
\hline Orange (To-F) & 6 & $2.30-1.46$ & $3.90 \times 10^{3}$ & 0.81 & 24.25 \\
\hline Light Bronze (MH-T) & (4) & $1.58-1.63$ & $3.76 \times 10^{3}$ & 0.35 & 9.12 \\
\hline Dark Blue (MH-T) & (6) & $1.58-1.63$ & $2.58 \times 10^{3}$ & 6.18 & 160.77 \\
\hline $\operatorname{Red}(\mathrm{To}-\mathrm{F})$ & & $2.30-1.46$ & $5.30 \times 10^{2}$ & 1.29 & 95.07 \\
\hline Blue (To-F) & & $2.30-1.46$ & $1.93 \times 10^{2}$ & 2.91 & 2.91 \\
\hline Green (MH-T) & (6) & $2.17-2.20$ & $1.30 \times 10^{2}$ & 3.66 & 91.43 \\
\hline Maroon (To-F) & & $2.30-1.46$ & \multicolumn{3}{|c|}{ Difficult to decipher signal from noise } \\
\hline Green (To-F) & & $2.30-1.46$ & \multicolumn{3}{|c|}{ Difficult to decipher signal from noise } \\
\hline
\end{tabular}

Table 1: Table of average mass normalised TL yield for each bead type from both manufacturers Mill Hill, Japan and Toho, Czech; ordered by descending mass normalised average TL yield. Uncertainty in diameter of beads $\pm 0.01 \mathrm{~mm}$, precision of digital caliper. $\mathrm{F}$ and $\mathrm{T}$ correspond to the bead finish either being F-frosted or T-transparent. 


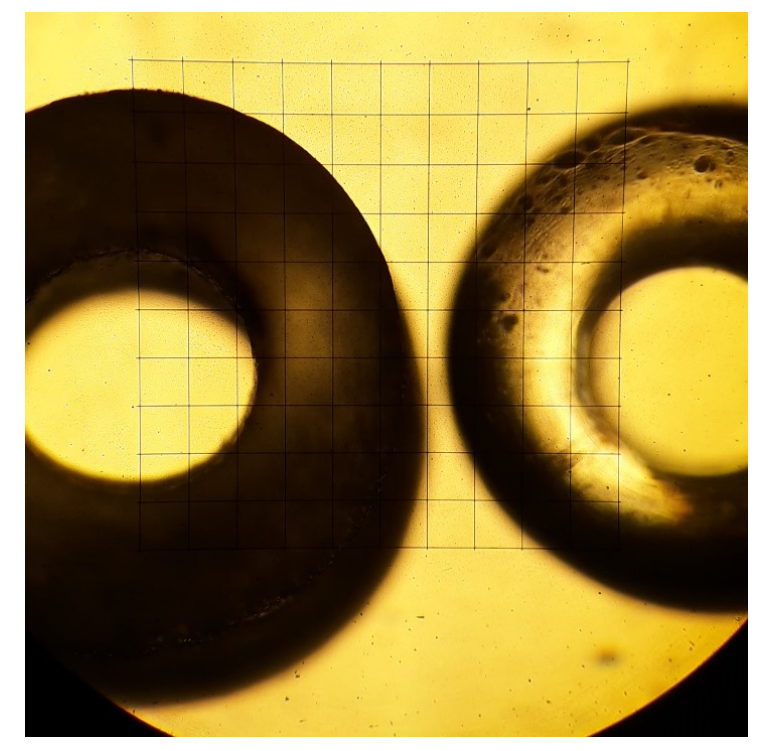

Figure 1: Magnified image of a frosted (referred to herein as white) Toho, Czech Republic bead (left) and a clear Mill Hill, Japan bead (right) at magnification $\times 5$, using an Olympus Japan BH2-MA-2 Microscope.

\subsection{Annealing}

Prior to annealing beads are strung on to a either stainless steel, aluminium or gold wire, depending on the inner diameter of the bead, for ease of handling. The string of beads were annealed in a Pickstone oven (Island Scientific Ltd, Ventnor, UK) equipped with a Eurotherm controller/programmer type 815 by heating to in excess of $400{ }^{\circ} \mathrm{C}$ at a rate of $600{ }^{\circ} \mathrm{C} /$ hour, then maintained for an hour and left to cool naturally in order to reduce the risk of stress fractures and associated strain-related defect generation.

\subsection{Storage}

Prior to irradiation and readout, measures need to be taken to reduce the amount of light to which the beads are exposed, to reduce the likelihood of filling superficial traps. The string of beads are wrapped in aluminium foil and stored in a lighttight box, the beads only being taken out for irradiation and subsequent readout of their thermoluminescent response.

\subsection{Irradiation}

Irradiation of the beads was carried out using a $6 \mathrm{MV}$ photon beam provided by a Varian electron linac (Varian Medical Systems, Palo Alto, CA), collimated to yield a uniform field of dimensions $15 \mathrm{~cm} \times 15 \mathrm{~cm}$ delivering a dose of $10 \mathrm{~Gy}$.

\subsection{Readout}

The thermoluminescence readout system used in these experiments is a Ris $\varnothing$ TL/OSL facility manufactured by the Ris $\varnothing$ National Laboratory, Technical University of Denmark (DTU). The Ris $\varnothing$ facility was operated in the preheat setting to acquire data throughout the heating cycle, recording the profile of the glow-curve. The beads were heated in a nitrogen environment, from room temperature to a maximum of $370{ }^{\circ} \mathrm{C}$ at a heating rate of $10{ }^{\circ} \mathrm{C} / \mathrm{s}$. The planchettes used to hold the samples were stainless steel, produced by the DTU-located manufacturers, DTU Nutech, with the beads placed with the hole axis perpendicular to the planchette surface when readout. The Ris $\varnothing$ TL/OSL machine has a sample size restriction, specifically in regard to the height of the samples that can be analysed, when located in the samples receptacle, being restricted to a maximum of $2.0 \mathrm{~mm}$. This resulted in some of the Toho, Czech republic beads being discounted from readout.

The Photo-Multiplier Tube (PMT) used in the Ris $\varnothing$ TL/OSL facility is a bi-alkali EMI 9235QB PMT, a choice predicated on the basis of the detection efficiency of luminescence for quartz and feldspar. The maximum detection efficiency lies between $200 \mathrm{~nm}$ and $400 \mathrm{~nm}$ with a wider detection range of $160 \mathrm{~nm}$ to $630 \mathrm{~nm}$ (DTU Nutech, 2015).

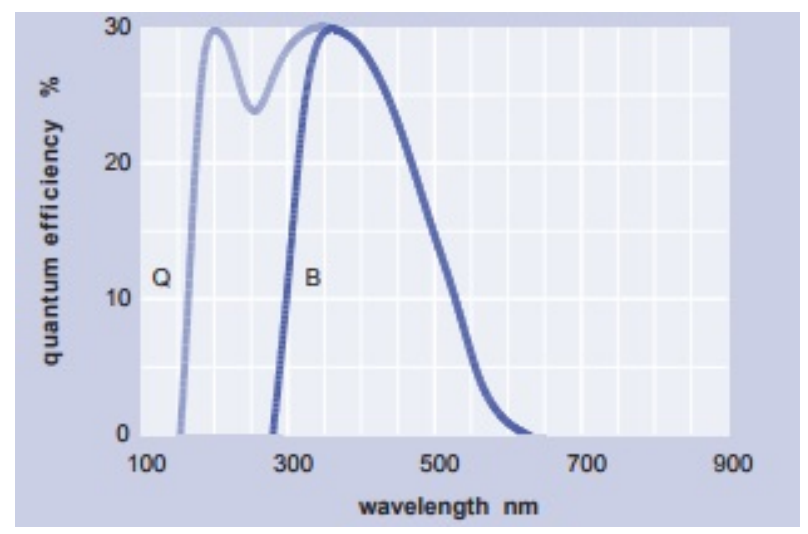

Figure 2: Quantum efficiency of bi-alkali EMI 9235QB PMT as a function of wavelength, shown by curve Q (fused silica) range $160 \mathrm{~nm}$ to $630 \mathrm{~nm}$ (ET Enterprises Ltd, 2010). 
Comparing this with the HARSHAW and TOLEDO readers, a shift is observed in the range of wavelength sensitivity, enhanced for detecting blue and UV luminescence, cognizance being taken of studies and TL emissions of quartz (DTU Nutech, 2015). Unlike the HARSHAW and TOLEDO, which record the presence of the preheat curve occurring at $\sim 160{ }^{\circ} \mathrm{C}$ expected to be due to a shallow trap in the silica and corresponding to a wavelength of $\sim 650 \mathrm{~nm}$ (Bachiller-Perea et al., 2015), the Ris $\varnothing$ TL/OSL facility produces a glow curve of a single peak, with the preheat peak lying outside the detection range of the PMT, see Fig. 2.

\subsection{Data Analysis}

Data is recorded and exported from a program designed for the output of the Ris $\varnothing$ TL/OSL named Analyst, it is exported into Excel where the glow-curves can be compared and used to identify anomalies in the curves. From the Excel templates a MATLAB code can then be used to sort and subtract background measurements for all glow-curves and to compare yields of different batches of readouts from the Ris $\varnothing$ TL/OSL. For these studies the background measurements consist of a series of glow-curves following the same heat readout as a sample but instead for an empty planchette, these several glow-curves are averaged and the background for each data point is calculated.

With the glow-curves were exported to Excel, the planchette profile glow-curves showed a signal beginning at $300{ }^{\circ} \mathrm{C}$, this was subtracted from corresponding silica bead glow-curves. However, this was not found to eradicate the shoulder displayed in the glow-curve. The typical glow curve for a clear transparent Mill Hill bead, Fig. 3, shows the shoulder occurring slightly before the heat cycle plateaus at $370{ }^{\circ} \mathrm{C}$, as circled.

It is suggested that the shoulder is likely due to an artifact produced due to the background luminescence of the planchette occurring at a lower temperature than it did in background readings for each planchette when comparing raw data to the background mitigated data. There is also the possibility that the shoulder could be due to a sec-

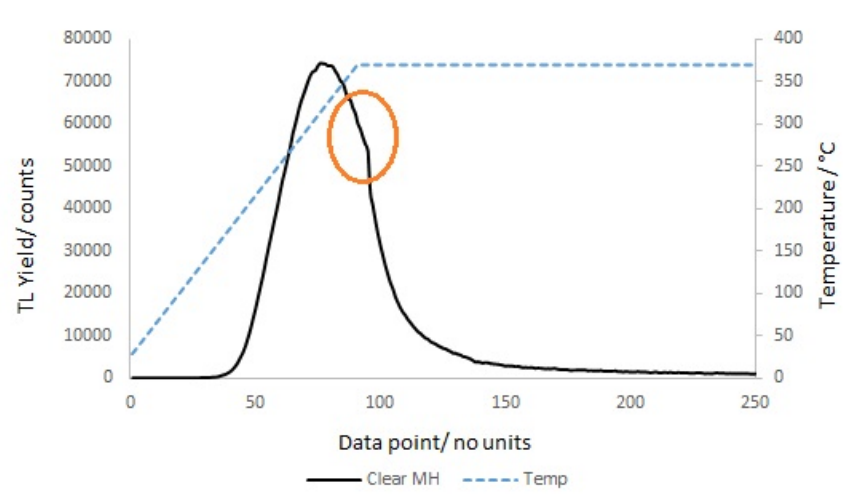

Figure 3: Typical glow-curve of a clear Mill Hill, Japan bead (transparent finish) with the heat cycle profile plotted as the dashed line. The circled area of the glow-curve shows the shoulder feature for this type of bead.

ond TL peak caused by a deeper electron trap in the material. This is a point for further study, there being a need to investigate the effect on the glow-curve of variation in heating rate and final temperature in the TL sequence of the Ris $\varnothing$ TL/OSL facility.

To keep the TL yield measurements consistent for these studies the TL signal contributing to the TL yield for each bead was measured to cut off point of the glow-curve, reducing the contribution of remaining background to the overall yield. For the beads that showed prominent shoulders (high TL yields - Clear MH, Clear Petite MH, Pink MH, White MH \& To) the cut off point was taken as the shoulder of the glow-curve; for the remaining beads the turning point of the decay of the glowcurve and exponential rise in the background contribution was taken as the cut off point, see Fig 4 . For the beads producing the higher yields this gave an underestimation of the TL yield by up to a $30 \%$ reduction, whereas the beads producing lower TL yields showed a fair representation of the TL signal with an underestimation of less than $5 \%$.

\section{Results and discussion}

\subsection{Glow-curves}

These studies have been conducted using different TL readers, therefore differences in the glowcurve of the silica beads were expected and were 
observed when comparing against the results of the studies of Jafari et al. (2014b). Previous studies have shown a glow-curve with a preheat curve at $\sim 160{ }^{\circ} \mathrm{C}$ and the main TL peak maximum occurring at a held temperature of $300{ }^{\circ} \mathrm{C}$ in using a heating rate of $25^{\circ} \mathrm{C} / \mathrm{s}$ (Jafari et al., 2014b). Utilising the Ris $\varnothing$ TL/OSL facility the glow-curves produced in the studies herein display a single TL peak, as stated in section 2.5 .

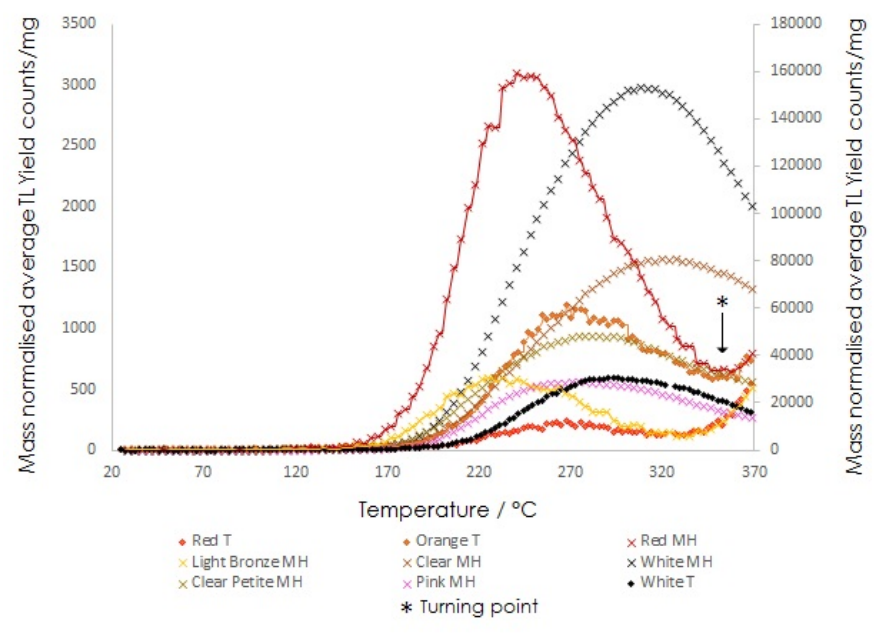

Figure 4: Typical glow-curves for different colours and manufacturers as a function of linearly increasing temperature. Beads; Red T, Red MH, Orange T, Light Bronze MH have TL yields read by the left scale; with the remaining beads Pink MH, White T, Clear MH, White MH and Clear petite MH display TL yields read from the right scale.

Another limiting factor found in use of the Ris $\varnothing$ TL/OSL facility is that the maximum heating rate that can be selected is $10{ }^{\circ} \mathrm{C} / \mathrm{s}$ - allowing the dosimetric medium to more likely acquire the recorded temperature but also taking time to obtain a glow-curve. This also results in a change of shape of the glow-curve, in particular a broader peak is produced. The glow-curve shown in Fig. 3 is that obtained for a transparent colourless bead produced by manufacturer Mill Hill, Japan that underwent the heat cycle described in section 2.5, this shows a well defined glow-curve with luminescence beginning to occur at $180{ }^{\circ} \mathrm{C}$ and peaking at $\sim 315^{\circ} \mathrm{C}$ and also displayed in Fig. 4 .

It has been observed that there are shifts in the average peak temperature when looking at the same colour, however these are minimal in comparison to the shifts observed from different colours, see Table 2. It appears that the peaks that occur at much lower temperatures correlate with those that produce the lower TL yields. There is a possibility that this correlation is due to the manufacturing process of the beads and that it can affect the capability of the beads to act as TL dosimeters.

\begin{tabular}{|l|l|l|}
\hline Bead Type & $\begin{array}{l}\text { Average Peak } \\
\text { Temperature } \\
\left({ }^{\circ} \mathrm{C}\right)\end{array}$ & $\begin{array}{l}\text { \% Error } \\
\text { in Mean }\end{array}$ \\
\hline Clear (MH-T) & 316 & 0.13 \\
\hline White (MH-F) & 312 & 0.06 \\
\hline White (To-F) & 286 & 0.14 \\
\hline Clear Petite (MH-T) & 282 & 0.06 \\
\hline Pink (MH-F) & 270 & 0.07 \\
\hline Orange (To-F) & 267 & 0.12 \\
\hline Yellow (To-F) & 265 & 0.15 \\
\hline Clear Blue (To-T) & 265 & 0.13 \\
\hline Red (To-F) & 262 & 0.13 \\
\hline Blue (To-F) & 262 & 0.43 \\
\hline Blue (MH-T) & 248 & 0.07 \\
\hline Green (MH-T) & 248 & 5.04 \\
\hline Red (MH-F) & 244 & 0.11 \\
\hline Dark Blue (MH-T) & 233 & 0.82 \\
\hline Light bronze (MH-T) & 230 & 0.14 \\
\hline Clear Green (To-T) & 170 & 1.11 \\
\hline
\end{tabular}

Table 2: Average Peak Temperature of glow-curves collected by the Ris $\varnothing$ facility by colour, displayed in descending order. $\mathrm{F}$ and $\mathrm{T}$ correspond to the bead either being F-frosted or T-transparent.

\subsection{Comparison of bead TL yield from two Man- ufacturers}

The motivation behind the bead manufacturer study was to observe which beads produced a greater TL yield and superior homogeneity within batches when produced and ordered in bulk. The data displayed in the sixth column of Table 1 was calculated as the standard deviation, $\sigma$, as a percentage from the mean TL yield values from irradiated samples in readout - this being believed to best represent the bead homogeneity, with the fifth column representing the error in the mean of the TL yields of the same bead type as a percentage. 
It is clear that if homogeneity of response is key to the application of these beads, as in dosimetry, that initial screening to TL response would be necessary. The required characteristics of the beads would guide the choice of which manufacturers beads to use. One qualitative result is that the Mill Hill, Japan beads were physically significantly more homogeneous than the Toho, Czech Republic beads.

\subsection{Colour study}

In irradiating different coloured beads, with expected variation in luminescent response, it is only to be expected in association that different TL yields will be obtained for the same dose. The differences in yield are also to be associated with the different dopants used in the beads, providing different depths for electron traps as well as the possibility of self-attenuation. A variety of coloured beads with varying finishes (transparent or frosted) were investigated, as shown in Table 1 . with the following colours not presented as the yields and homogeneity of glow-curves showed a indeterminable level of signal to noise for the majority of beads tested; clear green (To- $\mathrm{T}$ ), green (To-F) and maroon (To-F), with $\mathrm{T}$ and $\mathrm{F}$ corresponding to the transparent, $\mathrm{T}$, or frosted, $\mathrm{F}$, finish of the bead.

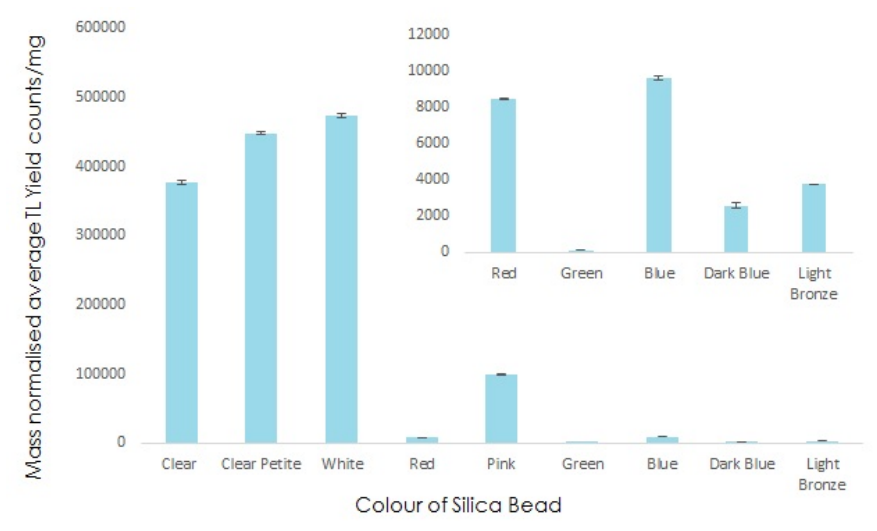

Figure 5: Comparative plot of mass normalised average TL yield for Mill Hill, Japan bead readout using the Ris $\varnothing$ TL/OSL. Insert displays TL yields of coloured beads with significantly smaller magnitude of TL yield on a more suitable scale. Error bars calculated by using the error in the mean.

The Mill Hill, Japan beads providing the great- est TL yield per unit mass were the colourless type, with the best yield obtained from that with the frosted finish. Of the coloured beads, the greatest yield was that from the pink beads, producing a yield that remained within a factor of 10 of the colourless beads, see Fig 5 .

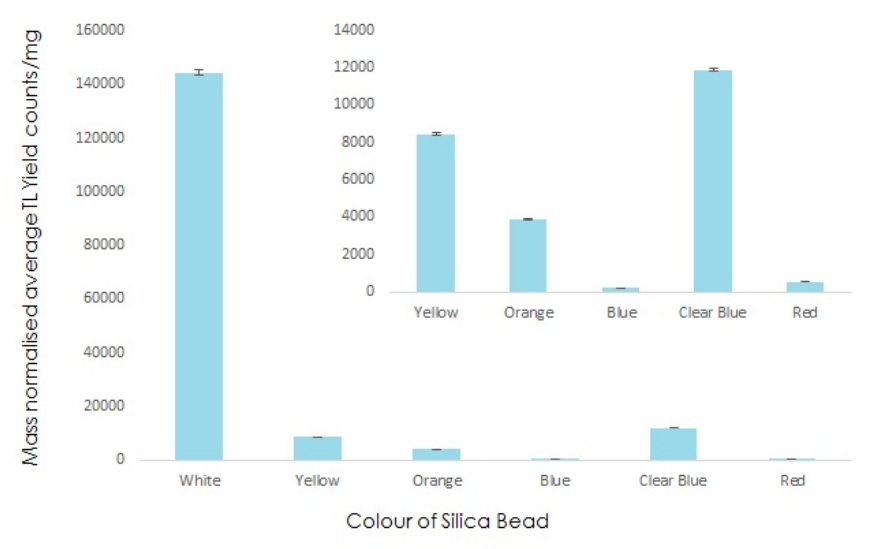

Figure 6: Comparative plot of mass normalised average TL yield for Toho, Czech bead readout using the Ris $\varnothing$ TL/OSL. Insert displays TL yields of coloured beads with significantly smaller magnitude of TL yield on a more suitable scale. Error bars calculated by using the error in the mean.

Investigation into the Toho frosted finish beads shows a significantly reduced TL yield across all of the coloured beads, as shown in Fig. 6, when compared against the transparent finish coloured bead yields shown in Fig. 5. The two batches of beads agree in the case that the greater TL response has been obtained from the colourless beads. The insert in Fig. 6 shows the Toho coloured beads TL response on an expanded data scale, showing the best yield to be that with a clear finish (clear blue).

Considering the TL yield of the green coloured beads it would appear that self-attenuation is occurring, representing the least attractive prospect as TLDs, not least when combined with the greater observed \% variation (deriving as this does from poor homogeneity in production of these sets of beads).

\section{Conclusions}

Comparing the different readers, different shaped glow-curves have been observed. In use 
of the Ris $\varnothing$ TL/OSL facility, previous evidence of shallow traps in doped silica, seen when using the other two reader types, are not detected by the PMT incorporated in the Ris $\varnothing$ reader. This can be considered to be a useful feature when using the Ris $\varnothing$ facility, with superficial traps (light and temperature sensitive) not recorded on the glowcurve and hence not contributing to the detected TL yield.

The most desirable beads to obtain the highest TL yield in use for doses of the order of 10 Gy are observed to be the colourless beads distributed by Mill Hill, Japan, with these displaying the smaller changes in TL yields from the average. A frosted finish does seem to offer slight improvement in the TL yield of irradiated colourless beads, with white Mill Hill, Japan beads showing a higher yield for that of the clear Mill Hill, Japan beads, thereafter the higher TL yields were produced from transparent beads. It is apparent that the colourless beads offer particular advantage as a robust, high spatial resolution, high dose sensitivity passive form of dosimetry, potentially at relatively low cost.

\section{Acknowledgments}

The authors would like to thank the technical staff in the Physics Department radiation laboratories at the University of Surrey for their advice and support in conduct of the experiments reported herein, as well as Queen Alexandra Hospital staff for irradiation of samples. K.L. would also like to credit SEPnet for funding the presented work.

\section{References}

Abdul Sani, S.F., Alalawi, A.I., Hairul Azhar, A.R., Mahdiraji, G.A., Tamchek, N., Nisbet, A.,Maah, M.J., Bradley, D.A., High sensitivity flat $\mathrm{SiO}_{2}$ fibres for medical dosimetry Radiation Physics and Chemistry 104, 134-138, 2014.

Alawiah A., Amina, Y.M., Abdul-Rashidb, H.A., Wan Abdullahc, W.S., Maahd, M.J., Bradley, D.A., An ultrahigh dose of electron radiation response of Germanium Flat Fiber and TLD-100, Radiation Physics and Chemistry 130, 15-23, 2017.
Bradley, D.A., Abdul Sani, S.F., Alalawi, A.I., Jafari, S.M., Noor, N.M., Azhar, A.R.H., Mahdiraji, G.A., Tamchek, N., Ghosh, S., Paul, M.C., Alzimami, K.S., Nisbet, A., Maah, M.J., Development of tailor-made silica fibres for TL dosimetry Radiation Physics and Chemistry 104, 3-9, 2014.

Bachiller-Perea, D., Jimnez-Reyd, D., Muoz-Martna, A., Agull-Lpeza, F., Ion beam induced luminescence in amorphous silica: Role of the silanol group content and the ion stopping power, Journal of Non-Crystalline Solids 428, 36-41 November 2015.

DTU Nutech, Guide to The Riso TL/OSL Reader, DTU Nutech, Denmark, August, 2015.

ET Enterprises, $51 \mathrm{~mm}$ (2") photomultiplier 9235B series data sheet, ET Enterprise Limited, https://my.etenterprises.com/pdf/9235B.pdf, ET Enterprises (c), 2010.

Jafari, S., Jordan, T.J., Hussein, M., Bradley, D.A., Clark, C.H., Nisbet, A., Spyrou, N.M., Energy response of glass bead TLDs irradiated with radiation therapy beams, Applied Radiation and Isotopes 104, 208-211, November, 2014a.

Jafari, S., Bradley, D.A., Gouldstone., C.A., Sharpe., P.H.G., Alalawi, A., Jordan, T.J., Clark, C.H.,Nisbet, A., Spyrou, N.M., Low-cost commercial glass beads as dosimeters in radiotherapy, Radiation Physics and Chemistry 97, 95-101, 2014b.

Mizanur Rahman, A. K. M., Zubair, H. T.; Begum, Mahfuza; Abdul-Rashid, H. A.; Yusoff, Z.; Ung, N. M.; MatSharif, K. A.; Wan Abdullah, W. S.; Amouzad Mahdiraji, Ghafour; Amin, Y. M.; Maah, M. J.; Bradley, D. A., Ge-doped silica optical fibres as RL/OSL dosimeters for radiotherapy dosimetry, Radiation Physics and Chemistry 116, 170-175 July, 2015.

Mizanur Rahman, A. K. M., Zubair H., Begum M., AbdulRashid H., Yusoff Z., Omar N., Ung N., Mat-Sharif K., Bradley D. A., Real-time dosimetry in radiotherapy using tailored silica fibers Radiation Physics and Chemistry 122, 43-47, 2016.

O'Keeffe, S., Woulfe, P., Sullivan, F.J., Radioluminescence based optical fibre sensor for radiation monitoring during brachytherapy, Proceedings of IEEE Sensors (2015), DOI 10.1109/ICSENS.2015.7370523, January 2016.

Rozaila, S.Z., Alyahyawi, A., Khandaker,M.U., Amin, Y.M., Bradley, D.A, Maah, M.J., Ge and B doped collapsed photonic crystal optical fibre, a potential TLD material for low dose measurements, Radiation Physics and Chemistry 126, 9-13, 2016.

Woulfe, P., OKeeffe, S., McCarthy, D., Grattan, M., Hounsell, A., Cronin, J., Lewis, E., Characterisation of radioluminesence based optical fibre dosimeter in radiotherapy beam applications, Proceedings of IEEE Sensors (2013), https://doi.org/10.1109/ICSENS.2013.6688478, 2013. 